\title{
Erratum to: " $\mathrm{MnO}_{2} / 3 \mathrm{MgO}$ Nanocomposite for Preconcentration and Determination of Trace Copper and Lead in Food and Water by Flame Atomic Absorption Spectrometry" [Journal of Analytical Chemistry 73, 470 (2018)] ${ }^{1}$
}

\author{
Gholamreza Khayatian*, Marzieh Moradi, and Shahed Hassanpoor** \\ Department of Chemistry, Faculty of Science, University of Kurdistan, Sanandaj, 6617973717 Iran \\ *e-mail: gkhayatian@uok.ac.ir \\ **e-mail: s_hassanpoor@guilan.ac.ir \\ Submitted May 7, 2018
}

DOI: $10.1134 / \mathrm{S} 1061934818150017$

In Figure 4:

should read "Nitric acid (0.1 M)" instead of "Nutric acid (0.1 M)"

Figure 6 should be:

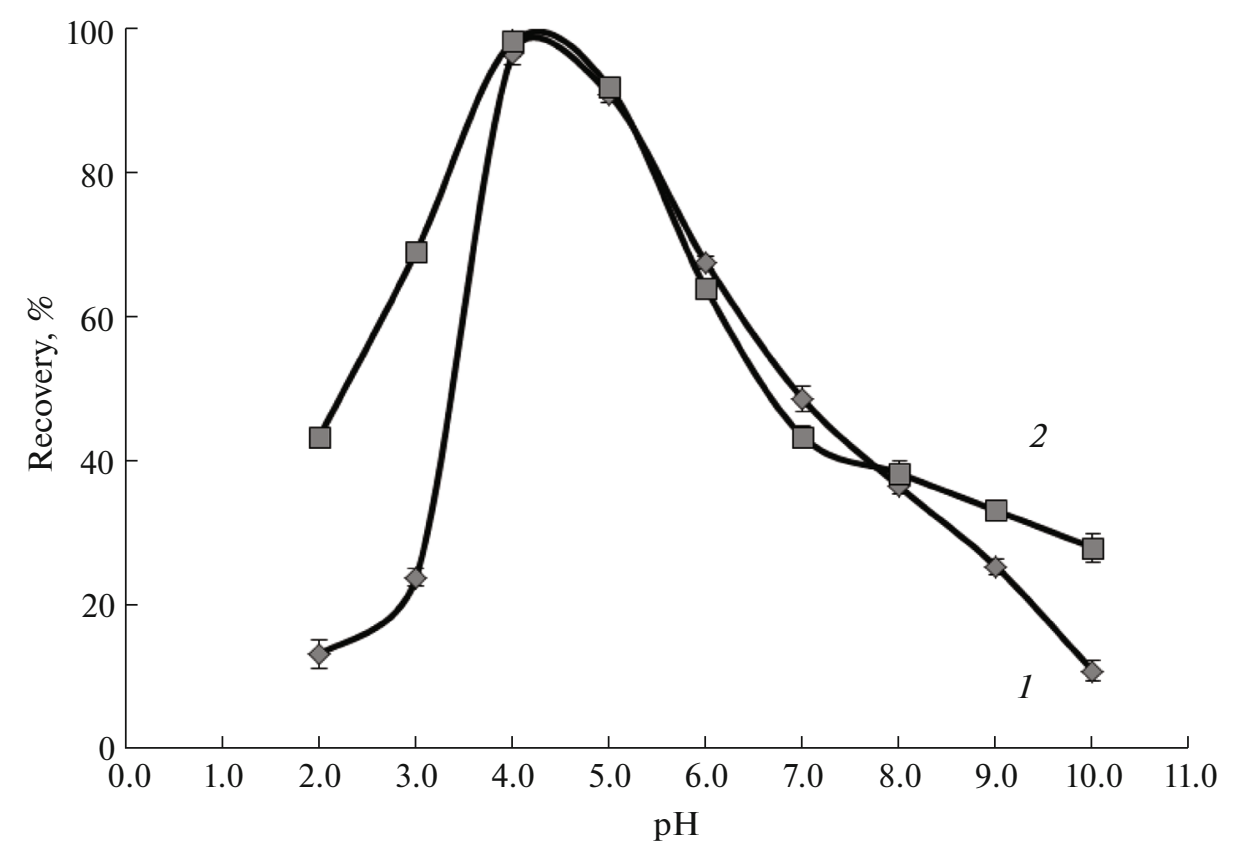

Fig. 6. Effect of $\mathrm{pH}$ on the recovery of copper (1) and lead (2).

\footnotetext{
${ }^{1}$ The article is published in the original.
} 